\title{
HACIA UN ESTATUTO DEL ELEMENTO ESPACIAL EN LA NOVELA
}

\author{
José ANTONio Alonso LERA \\ I.E.S. «Ágora». Alcobendas (Madrid)
}

\section{RESUMEN}

En este breve trabajo planteo una aproximación al elemento *espacio» en la novela, a partir de una perspectiva lingüistica. Parto del aspecto morfológico descriptivo para seguir con el esbozo de un sistema morfosintáctico del espacio y el análisis de las múltiples oposiciones posibles en este nivel, para culminar en la búsqueda de interpretaciones semánticas plausibles. Me propongo indagar y profundizar la compleja e inagotable semiología presente en los textos literarios. Abordo el estudio de la mitología, simbología y, sobre todo, de la polisemia del universo urbano en la novela desde una perspectiva multidisciplinar receptiva y abierta a diversas interpretaciones, que considero complementarias e iluminadoras y nunca excluyentes ni incompatibles.

PALABRas Clave: espacialización; morfología espacial; sintaxis espacial; semántica espacial; polidimensional; pasión fántica.

\section{ABSTRACT}

In this survey I aim to put forward a notion of the element *space in the novel from a linguistic perspective. I will begin with the descriptive-morphologic aspect, then draw an outline of the morphosyntactic system of space and tackle the analysis of the manifold possible oppositions at this level; finally I will try to search for plausible semantic interpretations. My purpose is to investigate and go deeply into the complex and inexhaustible semiology of space in literary texts. The aim in this approach to mythology, 
symbology and, above all, to polysemy of urban space. in particular, is, from an open and multidisciplinary perspective, to welcome its various interpretations, which I consider complementary and enlightening rather than incompatible or preclusive.

KEY wORDS: Spatialization; Morphology of space; Syntax of space; Semantics of space; polidimensional; showing passion.

Como punto de partida considero necesaria una aproximación al elemento «espacio» desde una perspectiva lingüística; desde lo concreto, lo morfológico-descriptivo podemos avanzar en el esbozo de un sistema morfosintáctico del espacio y en el análisis de las múltiples oposiciones posibles en este nivel, para luego proseguir y culminar en la búsqueda de interpretaciones semánticas plausibles; admitiendo, de antemano, la dificultad, trato de indagar y profundizar en la compleja y abierta semiología y hermenéutica del espacio - sobre todo el urbano- presente en los textos literarios.

En los textos narrativos del género novela (a veces también en el cuento) el espacio juega cada vez más un papel preponderante y esencial; éste es el caso patente en muchas obras del realismo literario del XIX. Ya no es solamente el a priori abstracto, implícito, atemporal y convencional, el continente necesario para sustentar la acción de los personajes, el simple decorado o escenario en el que transcurren los acontecimientos narrados en la ficción.

El elemento espacial en muchas novelas del xix y xx es mucho más, es un elemento central sobre el que pivota gran parte de la estructura novelesca; ya no es un elemento secundario más (la ancilla narrationis que menciona G. Genette), sino una unidad estructural de primer orden, de hondas implicaciones con los otros elementos (personajes, acción y tiempo) y con los demás ingredientes narratológicos (diálogo, descripción, narración, focalizadores, narradores, lectores...), apuntadas por Antonio Garrido (1996: 207-237). Adquiere un protagonismo de primera magnitud frente al pobre papel que se le concede en épocas anteriores, en la novela bizantina o caballeresca por ejemplo. El espacio cobra su verdadero perfil e identidad que le reconoce Bajtin en su teoría del «cronotopo» (1978: 230-260)'. La razón esencial es el ser ahora un espacio explícito y real representado.

En la novela contemporánea no es sólo ampliamente descrito, sino narrado y comentado. El escritor parece tener la intención de hacerlo patente y presente a la vista, a la mente e imaginación del lector, con la perfeccionada técnica de la narrativización en el tiempo. Además el espacio aparece profundamente semantizado en los diversos niveles narrativos, adquiriendo una dimensión y complejidad nuevas. Esta importancia y nuevo perfil se aprecia en las palabras de Carmen Bobes (1993: 196): «El espacio, como el tiempo, puede entenderse como una categoría gnoseológica que permite situar a los objetos y a los personajes por referencias relativas. Es también un concepto que se alcanza mediante percepciones visuales, auditivas, táctiles y olfativas».

En los escritores realistas (Balzac, Dickens, Flaubert, Zola, Galdós, Clarín...) las intenciones mostrativas o fánticas del espacio, concretamente del huc et nunc del espacio

1 La teoría del cronotopo de Bajtin hunde sus raíces y se alimenta directamente de la concepción kantiana del espacio y el tiempo, los a priori de nuestra sensibilidad y del conocimiento perceptibles ya en Hume. 
urbano, son detectables en el gran esmero por la descripción de objetos — pasión cosística- y de lugares, ligado tal vez a su gran esfuerzo por aferrarse al presente, por apresarlo y sustraerse a su fugacidad.

El espacio no es sólo simple escenario, marco circunstante de las acciones narradas, es también contenido, objeto y sujeto del discurso literario en el nivel de la fábula, de la historia y del texto. El espacio urbano es sujeto y objeto explícito de una concepción espacial peculiar que está en el origen de las imágenes míticas de las grandes ciudades contemporáneas (visible en el caso de novelas como Ferragus, Le Père Goriot, Illusions perdues, Splendeurs et Misères des Courtisanes; David Copperfield; La desheredada, Fortunata y Jacinta, etc.)

La nueva dimensión del elemento espacial que reclama un estatuto de rango superior en la narrativa contemporánea la expresa $\mathrm{H}$. Mitterand en los siguientes términos (1980: 189): «Dans le roman classique tel que Balzac nous en offre l'exemple, l'espace, et notamment l'espace de la ville, et plus précisément encore l'espace de Paris, est tout à la fois représenté et commenté: d'un côté, il se trouve inclus dans l'univers raconté, au moins en qualité de circonstant des actions narrées; d'un autre côté, il fait l'objet d'un discours, explicite ou implicite, s'inscrivant dans une conception, une vision, une théorie de Paris. L'espace parisien est doublement signifié, doublement sémantisé. Le texte du roman le désigne, le figure, et il lui donne du sens, de multiples façons et sur de multiples plans.» Tales términos aplicados a las obras de Balzac, en mi modesta opinión, se pueden hacer extensivos a obras de Galdós, Zola, y en cierta medida a las de autores como Dickens o Dostoievski.

El impulso expansivo del espacio, la tendencia a la espacialización dentro de la novela contemporánea han sido destacados por críticos como J. Frank y R. Gullón; G. Bachelard ha profundizado en una psicología sistemática de los lugares o espacios de nuestra vida íntima y sus valores simbólicos; G. Poulet o G. Durand han explorado los espacios cerrados y abiertos, delimitados o extensos, subterráneos o aéreos, etc.; Philippe Hamon ha estudiado los lugares cibernéticos de intercambio de información...

En este momento se echan en falta los estudios de análisis y examen de las interrelaciones de esos espacios con todos los demás que constituyen el sistema topológico global de una novela; esta tarea la intentamos bosquejar tras un estudio previo de tipo gramatical, que aborda los planos morfológico, sintáctico y semántico. El estudio aislado de los topoi literarios es incompleto e insuficiente y hemos de buscar un análisis más global que dé cuenta de la estructura topográfica en su conjunto, de las correlaciones con el entramado de componentes narrativos; las interrelaciones espacio-personajes, espacio-acción, espacio-tiempo son profundas y merecen ser indagadas.

Apelamos a la necesidad de partir de un inventario topográfico mínimo y operativo del espacio urbano; por ello creemos útil inventariar y describir una morfología que pueda servirnos para el análisis y estudio literario. Nos parece acertada la sugerencia de $\mathbf{H}$. Mitterand (1980:193): «Il nous manque un répertoire morphologique et fonctionnel des lieux romanesques, analogue à celui que propose $\mathrm{Ph}$. Hamon pour les personnages.»

En esta propuesta de inventario recogemos las unidades morfológicas básicas de la estructura espacial, desde un punto de vista más práctico que teórico, que son susceptibles de constituir las coordenadas topográficas de la acción de una novela de espacios urbanos. Estas unidades pertenecen a un espacio-ficción y tienen, en gran medida su co- 
rrelato concreto y cierto en las ciudades del XIX y XX, es decir, una fuerte dosis de referencialidad.

No se puede olvidar que en la funcionalidad de las unidades morfologicas en que se fragmenta el espacio urbano aparece la temporalidad, el factor época, que tiñe la compleja semiología, que añade los rasgos peculiares propios a esas calles, paseos, avenidas, salones, teatros, cafés, etc. - la cronotópica peculiar de cada novela-. Esa carga de semiología social y cultural del siglo y de la época es inseparable de esa historia concreta de la ciudad, enraizada en la propia historia y cultura de cada país.

En la semantización de los miniespacios de la ciudad, de los distintos elementos morfológicos más significativos, han entrado en juego multitud de factores de tipo topográfico, arquitectónico, histórico, social, económico, moral, religioso, psicológico, antropológico. La mente del poeta o novelista - cual crisol caleidoscópico- los moldea y disfraza de mil caras en virtud de su poder creativo, que juega con todo tipo de asociaciones prosopopéyicas, metonímicas, analógico-metafóricas...

Sin duda, a los factores originarios topográficos, geográficos, antropológicos se han añadido los históricos, sociales, económicos, etc. que conforman finalmente el perfil moral y psicológico de cada unidad espacial (zona, barrio, calle, plaza, etc.). En un principio ha primado el espacio bien situado, estratégico (la parte alta/la parte baja; zona norte/zona sur; el centro/la periferia; lo amplio/lo estrecho...). Más tarde el propio desarrollo de la ciudad y los valores asignados a los diferentes espacios han determinado el reparto de los lugares a las capas sociales (nobles, comerciantes, artesanos, obreros, criados, etc.) que han contribuido a configurar una fisonomía propia de tipo psicológico y moral. Poco a poco, cada elemento espacial semantizado, cargado de significado y connotaciones, ha empezado a formar parte - pletórico de vida propia - de un discurso colectivo convencional aceptado, en muchos casos previo a su incorporación al discurso novelesco y literario. El escritor, en muchos casos, no hace sino resaltar y dar vida literaria a lo que es ya sentido y percibido en el ambiente como acerbo común. En la sensibilidad o mente privilegiada del poeta o novelista cristalizan ciertas imágenes míticas colectivas ${ }^{2}$.

Apuntamos desde este momento que en la gramática espacial apreciamos cierta imbricación e interconexión entre lo morfológico, lo sintáctico y lo semántico, según tendremos ocasión de ir mostrando.

Hay que destacar que en el plano de lo morfológico, escritores como Balzac, Dickens y Galdós apuran su desarrollo hasta un grado de perfección casi inigualable, superando a otros novelistas anteriores o contemporáneos (H. Fielding, J. Austen, V. Hugo, H. James, etc.). Sería prolijo enumerar las decenas de elementos o unidades constitutivas de la morfología del espacio urbano a sumar a calles, avenidas, jardines, parques, plazas, teatros, cafés, etc., acerbo común de tantos habitantes del París, Londres y Madrid del XIX, y que, gracias a la impronta especial y a la portentosa capacidad figurativa y creativa de estos novelistas, han pasado a ese fondo o poso común que sustenta y reaviva esas mitologías urbanas presentes en el subconsciente y la mente de mujeres y hombres lectores de novelas.

2 Coincidimos en este punto con la manifestación de Andrés Amorós (2001: 76): «En cierta medida, el desarrollo mental de un escritor recapitula el de toda la raza humana. Al escribir desciende a un fondo oscuro que es común a todos y de alli saca mitos que reconocemos porque también los lectores los hemos conocido en nuestros propios descensos». 
Muchas de las novelas de estos escritores (Ferragus, Le Père Goriot, Illusions perdues, Splendeurs et Misères des Courtisanes, La desheredada, Fortunata y Jacinta, etc.) aúnan y reúnen tanto los elementos reales físicos, mensurables y observables en el paisaje urbano (lo que denomino realidad A) como un conjunto de imágenes mentales, que los novelistas dotados de talento y sensibilidad, se han forjado y han cuajado acerca de la ciudad. Corresponde a la morfología analizar dichos elementos físicos observables en la geografía urbana con un sesgo ante todo descriptivo. En la sintaxis espacial y, sobre todo, en la semántica y polisemia del espacio urbano intento estudiar esas imágenes mentales de índole mítico, legendario, religioso, literario, etc. que el espacio de la gran ciudad suscita y despierta en la mente del novelista y de los hombres (lo que denomino realidad B).

Por otra parte, las imágenes de la ciudad que crea y capta el novelista no son totalmente ajenas ni distantes de las que captan de tal fenómeno los estudiosos de la ciudad, que encaran dicha realidad como un hecho complejo y plurívoco. En tal espacio confluye, por un lado, lo presente físico y observable (A) y, por otro, lo mental, transmitido, aprendido y heredado de la vida y del pasado (B). En el espacio literario de gran parte de las novelas no son incompatibles sino que conviven, tanto la práctica del realismo genético - más próximo a A-, como la del realismo formal -más cercano a B- (Darío Villanueva, 1992: 15-69).

En principio hay que subrayar que la complejidad del espacio de la ciudad no se puede agotar y circunscribir a lo meramente físico, descriptivo y morfológico. Un pensamiento similar en muchos puntos expone José Estébanez a la hora de intentar definir la ciudad desde la perspectiva de la Geografía humana, que supera lo físico e inanimado?

Tanto el novelista como el poeta que trata de la ciudad (Wordsworth, Baudelaire, Poe, Lorca...), pienso que, sin duda alguna, funden en su labor creativa el plano de lo real físico (realidad A) con el plano de lo mental e imaginario (realidad B: la ciudad vivida y conocida y luego imaginada y recreada como objeto artístico y literario).

\section{MORFOLOGIA ESPACIAL}

En una primera aproximación al espacio de la ciudad y su morfología encontramos todos aquellos elementos perceptibles por un transeúnte observador que recorre dicho espacio y distingue en él diferentes unidades urbanísticas que dan una forma especial que configura tal espacio. Para el observador superficial esos elementos constituyen un conjunto fragmentado, no estructurado, que podemos subdividir en elementos espaciales abiertos - que le permiten deambular y trasladarse libremente (calles, avenidas, paseos, plazas, jardines, parques, puentes...) - y en elementos espaciales cerrados -que su-

${ }^{3}$ Así se expresa el autor en sintonía con otros estudiosos (1988: 393): «No podemos olvidar que la ciudad es un hecho que se manifiesta en diversos planos, siendo uno de ellos el de la ciudad objetiva, como elemento de observación y medición mediante una serie de atributos físicos y sociales, (...) Pero otro plano es el constituido por un conjunto de imágenes que operan en la mente de los hombres que habitan la ciudad y en función de las cuales realizan unas actividades circunscritas en el tiempo y en el espacio. El ideal sería intentar fundir estas dos concepciones; la ciudad de los que viven en ella tal y como la perciben y la ciudad de los estudiosos, de los que tratan de analizarla como observadores exteriores. El lograr fundir estos dos planos es el reto actual de las ciencias sociales $(. .$.$) ».$ 
ponen una barrera e impedimento a su libertad de paso (casas, edificios, muros, monumentos de todo tipo...)-.

Si analizamos más en detalle todos esos elementos observamos que están fuertemente estructurados. Dicha organización, más o menos compleja, nos permite vislumbrar y aventurar una estructuración sistemática que gira básicamente en torno a oposiciones binarias. A partir de dichas oposiciones podemos considerar luego otras posibles clasificaciones de tipo ternario o de carácter más amplio.

Antes de introducirse en la ciudad el observador aprecia una clara separación del espacio exterior de la urbe frente al espacio interior. Esto lo constatamos ya en las expresiones del propio lenguaje que reflejan dicho corte espacial («llegó a», «entró en», «salió de», «se fue de»...). En esta oposición binaria inicial vemos que dicho espacio exterior a la ciudad presenta el rasgo distintivo de ser aparentemente informe, inarticulado, amorfo; digo aparentemente porque es cierto que en aquellas ciudades prerromanas el espacio exterior era más bien amorfo y llegaba a las puertas de la misma ciudad; cabían en él los espacios naturales abiertos y sin hollar aún por el hombre (montañas, mares, bosques, etc.).

Sin embargo, a partir del XIX, de la gran expansión del fenómeno urbano, del desarrollo de los transportes (ferrocarriles, carreteras, túneles, rutas marítimas...), hemos de indicar que la mano del hombre va imponiendo su impronta organizadora, violenta y destructora de los espacios naturales exteriores a la ciudad. Vías, carreteras, túneles, puentes, etc. todos ellos construcciones artificiales, han sido diseñados y creados por el hombre para poner en comunicación los lugares habitados (aldeas, pueblos, ciudades), invadiendo así y organizando, en gran medida, también los espacios exteriores.

El espacio interior de la ciudad aparece muy intensamente organizado y estructurado, refleja un espíritu y una civilización. La articulación morfológica incipiente en la ciudad prehelénica, recibió el impulso decisivo con los griegos y romanos, completándose con mayor complejidad tras la fuerte expansión de las metrópolis en los siglos XIX y xx.

Los griegos diferenciaron, racionalizaron el espacio de la polis, convirtieron el logos espacial en realidad urbana habitable, lo moldearon con tesón, arte e inteligencia, orientándolo a sus funciones sociales y culturales (plazas, templos, teatros estadios...); su labor la continúan los romanos con mejoras de salubridad, sanidad e higiene (pavimentación, alcantarillado, agua corriente, termas...).

El binomio predominante en la organización del espacio interno urbano se funda en la oposición espacio abierto/espacio cerrado, que responde a la función de uso común público y libre/uso particular o privado de sus moradores. Los muros, paredes, puertas, verjas, etc. delimitan de forma clara y tajante los dos tipos de espacio —cuestión de deslinde de espacios que intuyó con perspicacia Rousseau cuando trata el origen de la propiedad asociándolo con el comienzo de la vida en sociedad (Discours sur l'inégalité): «Le premier qui ayant enclos un terrain s'avisa de dire: Ceci est à moi, (...) fut le vrai fondateur de la société civile--."

Los espacios abiertos forman un entramado continuo que comprende calles, avenidas, paseos, plazas, jardines y demás espacios abiertos que comunican con el espacio exterior por medio de vías, carreteras, etc. Los espacios abiertos pueden adoptar formas variadas: circulares, cuadradas, rectangulares..., siendo la forma preferente la lineal o alargada, propia de calles, avenidas y vías, para facilitar la función principal de medio de paso o comunicación. 
Los espacios abiertos suelen enmarcar y rodear los espacios cerrados, que por esta razón son necesariamente discontinuos. Los espacios cerrados: casas, monumentos y edificios son de formas y dimensiones variadas, preferentemente geométricas -cubos, prismas, círculos, etc. Los muros exteriores marcan el plano de delimitación fronteriza con los espacios abiertos exteriores (calles, avenidas, plazas, jardines, etc.).

Los espacios cerrados generalmente están cubiertos y presentan al exterior puertas, ventanas, verjas. La razón de ser y las funciones de los espacios abiertos y cerrados dentro de la ciudad tienen una tradición y una historia tan larga como la de las propias ciudades.

Los espacios abiertos acogen una gran plurifuncionalidad desarrollada a lo largo de la historia y detectable en las novelas: la comunicación, el tránsito, el movimiento, el paseo, el recreo, la recogida de información... Son espacios físicos de relación entre los distintos espacios cerrados o los abiertos dentro de la ciudad, o los exteriores a la propia ciudad.

Los espacios cerrados, en cambio, albergan la vida privada, la familiar, las actividades profesionales, artísticas, religiosas, y otras como el ocio, el descanso, el juego, etc.

Dentro de los espacios cerrados existe una clara división entre los privados y los públicos. El subconjunto de los espacios cerrados privados está constituido por toda clase de viviendas de tipo individual, familiar o colectivo (pisos, apartamentos, casas, mansiones, edificios, locales, conventos, colegios, palacios...). El subconjunto de espacios cerrados públicos está formado por espacios de acceso más o menos libre, gratuito o no (teatros, museos, iglesias, bibliotecas, cafés, hospitales, hoteles, pensiones, estaciones, restaurantes...).

La morfología propia de cada uno de los distintos miniespacios urbanos que vamos nombrando es variada y sujeta a modas y épocas, en consonancia con las funciones específicas asignadas, no obstante podemos decir que conoce un desarrollo reciente de gran amplitud y cierta uniformidad - siglos XIX y $\mathrm{xx}$-, tras la expansión demográfica y la gran eclosión urbanística surgida a raíz de la Revolución industrial.

Sería deseable abordar aspectos de tipo cultural, histórico, artístico, urbanístico... para comprender y profundizar en el fenómeno de la espacialidad urbana; existen distintos grados de desarrollo histórico según países y latitudes. El paisaje urbano y su morfología cambia a veces mucho de un siglo a otro; no es la misma la morfología de las ciudades europeas, norteamericanas, sudamericanas o asiáticas. La aparición de complejos industriales, portuarios, comerciales, deportivos, de ocio, etc. es típico del XX. Muchos de estos datos, derivados de un momento histórico, de una cultura y civilización aparecen reflejados en el espacio, acciones y ocupaciones de los personajes de las novelas contemporáneas.

Son también de gran interés en muchas novelas los lugares de transición o intermediación entre espacios cerrados, entre los abiertos o entre unos y otros, los de transición del espacio de la ciudad al exterior de la misma (puertas, ventanas, azoteas, balcones, terrazas, pasillos; parques, jardines, puentes, plazas, cruces, lagos, ríos, etc.). Es distinto el papel concedido en cada novela a estos miniespacios, lo que puede ser digno de estudio. (En Dickens juega un papel relevante el río Támesis, en Dostoievski el pasillo, en Balzac y Galdós el parque y el jardín - Our Mutual Friend, Crimen y castigo, Eugénie Grandet, Illusions perdues, La desheredada-, etc.). 
Las puertas y ventanas presentan el misterio, el suspense, la dualidad y ambigüedad del dios Janus romano, pueden cerrar o abrir los espacios: los reales -tridimensionaleso los mentales e imaginarios - polidimensionales-. La situación y la psicología de los personajes de un lado o de otro, dentro o fuera de tal espacio, alcanza al lector de forma inminente y sutil convirtiéndolo, ya en mero espectador, ya en voyeur interesado (sirvan de ejmplo los personajes protagonistas de The Mill on the Floss de G. Eliot, Madame Bovary de Flaubert, La Jalousie de Robbe-Grillet, Entre visillos de C. Martín Gaite...).

Por lo que respecta a los parques y jardines, los tan anhelados espacios urbanos, ofrecen para el habitante de la ciudad -ya se trate del jardín privado (David Copperfield, Eugénie Grandet), ya del público (Illusions perdues, La desheredada)- la magia prodigiosa y la paradoja de contener y resumir el espacio abierto y natural, por definición externo a la ciudad, dentro del espacio urbano, que desde un principio fue espacio artificial de destrucción del edén, de la naturaleza libre, sin muros ni calles ${ }^{4}$.

El intento de integración de la naturaleza dentro de la ciudad es a la vez miniaturización, domesticación y desnaturalización, al menos en la versión del jardín renacentista o a la francesa; fenómeno que trata, describe y narra bellamente focalizado Galdós en La desheredada (1994: 511-512): «(...) Después de admirar el afeitado parterre, fueron a dar la vuelta al estanque grande, que es un mar de bolsillo, como decía Miquis».

Otra oposición de gran rendimiento en la organización del espacio de la urbe es la de zonas bien situadas, céntricas/zonas alejadas, periféricas o suburbiales. Estas últimas relegadas a los personajes más menesterosos y sede de episodios tristes y lamentables ( $\mathrm{Da}$ vid Copperfield, Our mutual friend, La desheredada, Tiempo de silencio, etc.).

Pueden darse otras oposiciones útiles -dependiendo de cada novela- dentro de los distintos barrios o zonas de la ciudad. A título de muestra indicamos algunas de interés: zona norte/zona sur; zona este/zona oeste; zonas altas/zonas bajas... En muchos casos las oposiciones ofrecen un carácter ternario: barrios nobles / de clase media /plebeyos, etc.

El conjunto de oposiciones lo oriento al campo lingüístico-semántico y a nuestro propósito de estudio literario y aclaro que no pretende ser exhaustivo ni de precisión matemática. Resumo las oposiciones básicas, que en ningún caso tienen carácter cerrado ni dogmático, en el siguiente esquema:

a) Oposiciones de carácter morfológico, físico, topográfico, arquitectónico:

- Espacios dentro de la ciudad/espacios exteriores a la ciudad o naturaleza.

- Espacios abiertos de la ciudad/espacios cerrados.

- Espacios cerrados privados/espacios cerrados públicos.

- Espacios de transición de los edificios/espacios de transición abiertos.

- Zonas urbanas céntricas/zonas alejadas o periféricas.

\footnotetext{
4 Es interesante el estudio de Finney Gail (Garden Paradigms in $19^{\text {th }}$ Century Fiction) que tipifica de forma un poco estrecha la gran variedad de modelos de la novela decimonónica francesa, inglesa y alemana. Teresa $\mathrm{Zu}$ biaurre (2000: 193) trata también el tema del jardín y su múltiple semántica, que enriquecen autores como Galdos, los simbolistas y modernistas: «El jardín realista hereda de la tradición e incorpora para sus fines narrativos ciertos estereotipos convencionales. Permanece el concepto de jardín como locus amoenus y se siguen cultivando los espacios míticos del paraíso o edén cristiano y de la arcadia de los clásicos. (...) Ciertamente el jardín como enclave amoroso es uno de los más tenaces estereotipos espaciales, y de él (...) se sirve ya profusamente la novela del realismo para ensayar ciertas variaciones innovadoras».
} 
b) Otras oposiciones de tipo complementario, en las cuales a lo topográfico se suma una coloración de sesgo antropológico, religioso, histórico, socioeconómico, psicológico, etc.:

- Barrios o zonas norte/zona sur. Barrios o zonas oeste/zona este.

- Barrios o zonas altas/zonas bajas.

- Barrios o zonas nobles/barrios medios/barrios plebeyos.

- Barrios o zonas residenciales/zonas de ocio y paseo/zonas de trabajo o industriales.

- Barrios de valor histórico y artístico/zonas de mínimo valor histórico o artístico, etc.

Nuestro propósito no es agotar las posibles oposiciones analizables; éstas tienen una finalidad descriptiva y operativa. Ciertos novelistas privilegian la oposición zonas altas/bajas (Dickens, V. Hugo), otros las oposiciones de tipo socioeconómico (Balzac, Galdós, Zola); en algunas novelas se observan más connotaciones antropológicas, psicológicas, en otras más las de tono religioso, mitológico, literario, cultural...

La morfología de las grandes metrópolis (Londres, París, Roma, Madrid, Buenos Aires...) no pertenece de forma exclusiva a la época contemporánea - XIX y XX-, sino que arranca mucho antes en la Historia; lo cual suele tener su incidencia en la relación de los personajes con los distintos lugares o barrios nombrados en las obras. Nuestra mentalidad no arranca ex nihilo, se sustenta y alimenta de una tradición milenaria, que asigna lugares a unas personas u otras, a unos quehaceres (acciones) o a otros.

Lo antropológico se imbrica en lo histórico y cultural; así, de forma general, el palacio, casa o piso - lugares cerrados - han sido asignados en la tradición literaria a la mujer (desde Homero, pasando por los cantares de gesta, la novela caballeresca, la novela realista del XIX, etc.). La vida de las heroínas transcurre casi por entero dentro de los muros de espacios cerrados; en cambio los hombres han gozado de libertad de movimiento - novelas de viajes, de aventuras - por todos los espacios (los de la ciudad y los abiertos de la naturaleza).

La total autonomía y libertad de movimientos frente a la ausencia de tal libertad ha sido pauta y patrón cultural, antropológico y literario, que ha prevalecido como gran tópico, a pesar de alguna excepción para confirmar la regla. Todo ha contribuido a reforzar la semantización y diferenciación histórica y cultural «género-espacio», es decir, personaje femenino-libertad restringida y movimientos en espacios cerrados, personaje masculino-libertad total de desplazamiento por todos los espacios.

Merece la pena detenerse un instante en los que denomino espacios privilegiados -ciertas calles, avenidas, jardines, plazas, monumentos, etc.- frente a otros desdeñados o silenciados; suelen ser lugares típicos, atractivos, visitados, concurridos y admirados, que han contribuido a fortalecer el mito de esa ciudad, y que el genio, la perspicacia y la intuición de los grandes creadores ha incorporado y cristalizado en la mitología de las grandes metrópolis (Dostoievski-San Petersburgo, Raabe, Fontane-Berlín, Dickens-Londres, Balzac, Baudelaire-París, Galdós, Cela-Madrid, Clarín- Oviedo, Borges-Buenos Aires, Poe-Nueva York, etc.) 
SINTAXIS ESPACIAL

La propuesta de análisis sintáctico espacial narratológico que planteo --referido de forma particular al universo urbano- encuentra una justificación evidente en la trama de relaciones que se establecen entre los distintos lugares significativos que aparecen en cada novela. Estos lugares están conectados merced a los personajes protagonistas, que intervienen en ellos y cambian de espacio o escenario en el transcurso de la diegesis, de las acciones que se van sucediendo en el tiempo.

En la novela realista del XIX, que tomamos como base esencial para el análisis, el espacio general aparece fragmentado y seleccionado por necesidad, contrastado y compartimentado en miniespacios significativos: lugares de residencia o habitación, de trabajo, de tránsito, de paseo, de comunicación, de información, de relación, de ocio y diversión, etc. Al mismo tiempo en los miniespacios propios de cada novela que componen el espacio general global se sitúan y actúan unos personajes que viven determinadas experiencias: residen, habitan, trabajan, estudian, descansan, pasean, transitan, se relacionan, se divierten... A cada miniespacio y a través del tiempo se asignan determinadas funciones asociadas a él, ese «hacer» específico o quehacer dominante del personaje.

De la conjunción de espacio con función/es determinada/s y personaje concreto que vive, se mueve dentro o que va de unos espacios a otros, surge necesariamente un haz de relaciones dignas de estudio desde un punto de vista sintáctico. De hecho dentro del espacio general en que se enmarca cada novela -que a veces es presentado desde una perspectiva epifántica o panorámica - El Diablo Cojuelo, David Copperfield, Le Père Goriot - se ven primados unos lugares o escenarios más o menos mencionados, descritos, narrados, comentados..., que dan pie al continuo cambio de acción y decorado, y actúan como auténticos propulsores y pilares prolépticos de la diegesis ${ }^{5}$. Más aún tales cambios de lugar confieren un cierto espesor o densidad espacial — que denomino tetradimensionalidad - lo cual fundamenta y justifica la sintaxis espacial narrativa, al tiempo que nos invita a una interpretación semántica del tejido o entramado de los itinerarios resultantes.

H. Mitterand insiste en el espacio urbano intensamente organizado, estructurado, marcado y cargado de contenido semiológico (1980:197), también Carmen Bobes apunta ideas similares (1993: 207) y con gran perspicacia confiere al espacio la función de factor conformador o estructurante de la sintaxis narrativa (1993: 207): «La novela utiliza, pues, el espacio como un signo que remite a la situación de los personajes, (...) y además como un signo estructural que permite la construcción de la sintaxis narrativa».

En la propia organización de la topografía urbanística de la antigua ciudad griega, romana o medieval podemos intuir un logos o principio estructurador racional que subyace en la diferenciación de sus espacios en virtud de las distintas funciones o «hacer» asignados a los lugares: teatro, plaza, castillo, iglesia-catedral, plaza de mercado, etc. Ese

\footnotetext{
${ }^{5}$ Natalia Álvarez Méndez (Actas del XIII Simposio de la Sociedad Española de Literatura General y Comparada, La función espacial en la cuentística oriental y su papel en el relato contemporáneo, 2002: 451-456) habla también del gran protagonismo de que disfruta la dimensión espacial en los cuentos actuales (referido a cuentos de origen oriental y de vena fantástica de José M.' Merino, J. José Millás, Cristina F. Cubas, Pedro Zarraliki, Gonzalo Suárez...): «Este elemento adquiere una posición destacada en los relatos actuales influyendo y condicionando y con gran fuerza y en muchas ocasiones, el desarrollo de las historias».
} 
mismo principio racional estructurador -en sentido hegeliano- que continúa conformando los espacios urbanos contemporáneos nos puede servir de base para confeccionar y analizar las posibles sintaxis espaciales novelescas, para luego intentar indagar la semiótica asociada a esos signos literarios de la novela: lugares o miniespacios asignados de forma dominante a los personajes en conjunción con unos itinerarios o conexiones muy frecuentes y relevantes. En el confuso y aparente laberinto inextricable de la gran ciudad es posible desvelar semiologías plausibles.

H. Mitterand intuye el logos en el espacio de la ciudad, con sus calles y miniespacios tan fuertemente estructurados como pueden estarlo los fonemas en los sistemas fonológicos de las lenguas; el símil o comparación nos parece útil, acertado y digno de estudio (1980: 197): «La rue est donc prise dans une vision systématique de l'espace urbain tout entier. La rue Soly et la rue Bourbon sont en distribution complémentaire, autant que peuvent l'être les phonèmes d'un système phonologique avec leurs traits d'apparentement".

Creo que podemos partir de la calle como unidad base, lo que no obsta para considerar otras unidades espaciales relevantes en muchas novelas (plazas, casas, cafés, barrios, etc.). Los rasgos de parentesco o pertenencia de los distintos elementos espaciales los asimilo a las funciones o hacer típico, además dichos elementos pueden ser caracterizados por otros rasgos pertinentes y distintivos derivados de relaciones que constituyen oposición: calles o lugares nobles/ de clase media/ de clase plebeya; calles o barrios históricos antiguos/nuevos; zonas elegantes/ infraurbanas, etc. ${ }^{6}$.

En la aparentemente inocente estructuración espacial que está patente en cada novela, juega un papel importante lo que denominamos lo tetradimensional - la expansión del espacio en el tiempo- debido al pasado e historia propia del lugar, y por otra parte lo polidimensional -lo más específicamente cultural, literario y mental-, aspectos fundidos, latentes e imbricados en la producción literaria novelesca. Así se expresa Mitterand refiriéndose al espacio parisino (1980: 197): «la production de l'espace romanesque est gouvernée, préprogrammée par la pratique sociale, par le langage séculaire des lieux de Paris».

En la configuración y distribución de los espacios es determinante la distancia entre los mismos — que implica la ineludible dimensión tiempo-, su naturaleza, carácter y funciones. En las ciudades medievales amuralladas, con puertas que las clausuraban al exterior como a castillos, los itinerarios básicos de sus habitantes se podrían reducir a cuatro: la iglesia o catedral centraba el itinerario general de la vida religiosa y espiritual; la plaza del mercado centraba el itinerario de abastecimiento de víveres; las calles gremiales y artesanales orientaban los itinerarios laborales y comerciales; un cuarto tipo de itinerarios o desplazamientos más aleatorios y complejos giraba en torno a las relaciones de sociabilidad, de amistad o parentesco. Las pequeñas distancias, la escasez de espacio y su carácter cerrado explica la estrechez y escasa longitud de sus calles en trazado laberíntico, que sólo concede accesos múltiples a la catedral o a la plaza del mercado.

Las calles más anchas y alargadas de las ciudades del XVI y siglos posteriores son signo evidente del nuevo carácter de un espacio más abierto a la comunicación fácil y ágil

${ }^{6}$ El complejo sistema de oposiciones espaciales a definir en la urbe es abierto, pues creo que además de las derivadas de las distintas funciones, que son limitadas, también han de ser tenidas en cuenta las oposiciones que emanan de factores geográficos, topográficos, históricos, religiosos, socioeconómicos, morales, psicológicos, artísticos, etc. y que se suelen manifestar en gradación o contraste. 
entre grandes distancias, y nuevos itinerarios con medios de locomoción más rápidos... Las calles y avenidas del XIX y XX propician movimientos más lineales y rápidos, en consonancia con un ritmo de vida crecientemente más acelerado; por otra parte las plazas parques y jardines, que son ahora más amplios, favorecen los itinerarios circulares, sinuosos y lentos, más típicos de las ciudades medievales o musulmanas.

Cuando en una novela priman los itinerarios lineales y rápidos conectados a lugares que albergan quehaceres laboriosos o profesionales, tal hecho no es inocente o anecdótico, al contrario tiene fuertes implicaciones de tipo semántico o narratológico, que trasciende lo literario, tal como mostraremos más adelante. En David Copperfield Dickens nos presenta al protagonista realizando itinerarios rápidos, lineales, útiles, ajenos a toda semántica del ocio; los espacios aparecen mínimamente descritos y la preocupación mostrativa o fántica de los espacios londinenses está ausente en la novela, y las técnicas narrativas del autor para tratar el espacio londinense son sencillas. Como contraste, en Illusions perdues, Splendeurs et Misères des Courtisanes de Balzac, en La desheredada, Fortunata y Jacinta de Galdós, La Regenta de Clarín, etc. lo espacial es acogido con detalle y exuberancia, el deleite inherente a esos espacios contagia a narradores y focalizadores y alcanza a los lectores, y por ello las técnicas narrativas son ricas y variadas en sintonía con unas intenciones fánticas omnipresentes.

En los espacios abiertos discurren también los itinerarios de la interrelación social, la distracción, el ocio, la captación de información, funciones que los griegos potenciaron en torno a la plaza, ágora. En las novelas, según las preferencias o gustos del escritor, aparecen privilegiados ciertos miniespacios, y ello se destaca a través de distintas técnicas narrativas que no tienen por qué coincidir. En Dickens parece primar lo narrativo frente a lo descriptivo pero de forma concisa y selectiva; en Balzac lo descriptivo es detallado y ampliado y se alía con lo narrativo y los comentarios; Galdós ofrece la presentación de los lugares de forma escenificada, aderezándola con narradores varios, con focalización multiperspectivista de distintos personajes en movimiento de travelling multiangular.

Tras la primera lectura de una novela podemos captar con facilidad la tonalidad espacial prevalente, la mostración preferente de tales o cuales espacios o itinerarios asociados: los cerrados e íntimos (David Copperfield), los de recreo y ocio (Illusions perdues), los elegantes, los marginales y plebeyos (algunas novelas de Zola).

Para ahondar en la sintaxis de itinerarios espaciales propongo un rápido análisis de aquellos desplazamientos de mayor o menor frecuencia y que reflejan cierto espesor espacial dominante, ligado al protagonista principal, a sus próximos y a los antagonistas. Ordenados de mayor a menor frecuencia tendríamos los cuatro itinerarios siguientes:

b) Itinerarios rutinarios, habituales o casi cotidianos.

c) Itinerarios de cierta frecuencia, no habituales ni cotidianos.

d) Itinerarios ocasionales o de poca frecuencia.

e) Itinerarios únicos.

Tomamos como punto de partida de tales desplazamientos el lugar de habitación o residencia del personaje, que suele ser fijo; el lugar de destino o punto final de cada itinerario es, en cambio, variado: lugar de trabajo, domicilio de amigos, lugares de dis- 
tracción, espacios abiertos... Una consideración somera de los tipos a) y b) muestra una sintaxis espacial de coloración definida y determinante que suele indicar fuertes implicaciones entre los espacios, los personajes y los acontecimientos.

Los tipos c) y d) muestran cierto contraste con a) y b) y en ocasiones sirven para dar un viraje radical y abrir los horizontes espaciales de la novela (con ocasión de viajes al extranjero, a gran distancia, o con motivo de episodios de importancia capital —bodas, funerales, etc. 一).

Es necesario además precisar ciertas cualidades atinentes a los cuatro tipos de itinerarios, que son de gran transcendencia en la semántica, lo narratológico y lo literario. Los itinerarios pueden ser:

- Cortos/largos (según el menor o mayor trayecto recorrido).

- Circulares/lineales (más o menos sinuosos y sin trayecto ni destino prefijado, o bien directos y con destino fijo de antemano).

- Mencionados/resumidos/ detallados. Estos últimos pueden ser signo de las preferencias del autor, de la tonalidad espacial inequívoca de una obra, de miniespacios marcados o privilegiados.

- Narrados/focalizados/ comentados...

- Reales/fantásticos. Éstos alcanzan gran predicamento en ciertas novelas contemporáneas proclives a incluir espacios y paisajes irreales, de la imaginación, la fantasía, los sueños, el subconsciente, la ciencia ficción, las mitologías, etc.

\section{SEMÁNTICA ESPACIAL}

Mi punto de partida es el espacio literario e intento profundizar e indagar en la compleja semántica de los espacios urbanos, y buscar luego las posibles y plausibles explicaciones e interpretaciones, sin descartar a priori ninguna, por considerar que suelen ser complementarias.

La lectura de una novela nos proporciona los topoi característicos, los itinerarios dominantes del/ de los personajes principales. Hemos de distinguir cuáles se presentan como eufóricos o disfóricos, y, más importante aún, si lo son con respecto al protagonista, al narrador, al focalizador, al lector. También si hay coincidencia o divergencia en esta percepción positiva o negativa de los lugares -en algunos casos los focalizadores o los personajes obtienen percepciones erróneas de los espacios (casos extremos: Don Quijote, Isidora en La desheredada).

Otro aspecto, ya tratado por muchos críticos (Jakobson, R. Wellek, Bourneuf, etc.) y que en este momento sólo menciono, es el de las relaciones metafóricas y metonímicas espacio-personaje. Tales relaciones se remontan al menos a las mitologías y creencias del mundo clásico antiguo, que asociaban dioses y personas a lugares determinados: lares domestici, lares publici, dioses de los distintos lugares y espacios...

Conviene destacar el interés semántico del binomio espacial compatibilidad o bien incompatibilidad espacio-personaje. Consideremos quién influye más sobre quién, el personaje sobre el espacio o al revés. En general parece ser que son los personajes femeninos los que más influyen y mejor saben adaptar, moldear a su imagen y antojo, adecuar 
los espacios y hacerlos más agradables —caso de Howard's End de Foster y muchas novelas inglesas y alemanas-. En algunos casos también los protagonistas masculinos convierten los espacios en acogedores; el espacio revela su espíritu (así parece ocurrir con Wemmick en Great Expectations, que convierte la casa en su cálido y reconfortante castillo.). En muchos casos el genio original de un escritor se manifiesta en la subversión de los grandes estereotipos espaciales — con el personaje Micawber en David Copperfield asistimos a la subversión semántica del espacio de la cárcel, al hacer de éste un lugar agradable y de éxito; con Isidora, Galdós efectúa la subversión del tópico literario personaje femenino-espacio interior; en Nuestro padre San Damián, G. Miró hace lo mismo con el estereotipo de raíces antropológicas: lugares elevados-espacio noble y seguro frente a lugares inferiores-espacios plebeyos precarios y de peligro.

La buena adaptación e integración, que suele ser gradual, física y psíquica —ésta más lenta y compleja - suele traer aparejado como resultado la percepción y el sentimiento de unos espacios eufóricos, agradables o soportables; en el caso contrario los lugares resultan odiosos, insufribles y rechazables y se producen itinerarios de huida y alejamiento o sentimientos de repulsa. En muchas novelas del XIX y XX - las románticas en mayor número- se registra el caso de la alienación espacial del protagonista, de la inadaptación espacial del héroe dépaysé, del misfit...?.

En la rigurosa organización-jerarquización históricosocial que está en el origen de la fuerte semantización (C. Bobes, G. Poulet) del espacio urbano pueden producirse graves transgresiones espaciales por parte de personajes que invaden o se introducen en espacios que no le son propios por su status social; dicha transgresión desencadena la tensión y los acontecimientos dramáticos de la novela, hecho que también subraya $\mathrm{H}$. Mitterand (1980: 197): "Malheur à celui où à celle qui franchira les frontières de cette sémiologie urbaine». (ejemplos visibles en Pip-Great Expectations, Ferragus, Lucien-Illusions perdues, Isidora-La desheredada).

Existe el ejemplo muy frecuente en las novelas contemporáneas del personaje del campo, a veces de la pequeña ciudad, que se traslada a la gran ciudad, con la pretensión de instalarse e iniciar una nueva vida. En estas novelas se puede apreciar, reelaborado en múltiples variantes, el tópico del contraste campo/ciudad, que continúa la larga tradición literaria de menosprecio de corte/alabanza de aldea ${ }^{8}$.

En la adaptación espacio-personaje el factor socioeconómico es importante, lo que autoriza y avala las interpretaciones históricomarxistas de la novela (G. Lukács, L. Goldmann), dicho factor se puede superponer a lo antropológico y psicológico que abre las puertas a otros análisis. Es, en este punto, luminoso y profético el Tratado tercero de El Lazarillo, prodigio de identificación metafórico-metonímica del escudero con su lobrega y mísera mansión y de incompatibilidad de Lázaro con dicha mansión, símbolo de

7 Este fenómeno de hondas raíces psicologicas es estudiado por B. Hillebrand (1971), sobre todo en novelas de Keller, Stifter y Fontane, y es extensible al caso de las novelas románticas y a las del XIX y XX con protagonistas que se van del campo a la ciudad y pierden su espacio, al igual que le ocurre al hombre moderno, lo que el autor denomina: «die Raumentfrendung und Raumverlorenheit des modernen Menschen».

${ }^{8}$ Este tópico es también preponderante en novelas realistas y naturalistas latinoamericanas en las que se asimilan virtudes y bondades al campo y a la naturaleza y por otra parte maldades y vicios al ambiente urbano: $\mathrm{Ce}$ cilia Valdés de Cirilo Villaverde, Martín Rivas de Blest Gana, Sin Rumbo de Eugenio Cambaceres, Raucho de Ricardo Güiraldes, Ídolos rotos de Díaz Rodríguez... 
hambre y muerte. De forma implícita se anuncian ya las complejas interconexiones, tanto sociales y económicas como antropológicas y psicológicas del binomio espacio-personaje.

Es de gran interés indagar en la semántica de los itinerarios dominantes y de los lugares frecuentados. Los itinerarios del tipo: lugar de habitación-lugar de trabajo-lugar de habitación (a-b-a) suelen asociarse al trabajo, a los negocios, al esfuerzo, la diligencia, el mérito, la perseverancia... Itinerarios del tipo diferente: lugar de habitación-lugares abiertos o cerrados de ocio-lugar de habitación (a-c/d-a) suelen implicar una semántica de ociosidad, diversión, disipación, inconstancia, muy alejada de la anterior.

Con relación a los itinerarios anteriores podemos analizar los itinerarios rápidos, cortos/ largos, lineales, de objetivos concretos y definidos (negocio, trabajo, citas, etc.), y de otra parte los itinerarios largos, lentos, circulares o sinuosos que suelen indicar días de ocio, diversión, paseo, exhibición, captación de información, etc.

La semántica de ciertos itinerarios explica por sí misma el éxito o el fracaso de los protagonistas, el happy end o el final en desgracia. Dicho desenlace en la relación espacio-personaje pienso que se puede analizar en la línea de la dialéctica histórica hegeliana aplicada a las clases sociales y a sus espacios inherentes. En los siglos XIX y XX el hombre intenta derribar los muros infranqueables de la sociedad estamental del Antiguo Régimen'. La síntesis o resultado final de la lucha vital y espacial de clases e individuos nos ilustra sobre el peso e intensidad de las fuerzas en liza; Marx confiesa haber aprendido muchas de sus ideas leyendo a Balzac; G. Lukács y P. Barbéris encuentran acertado el análisis históricodialéctico de sus obras; por mi parte creo que se puede hacer extensible y aplicar a muchas novelas contemporáneas, no sólo a las del realismo y naturalismo del XIX.

En muchas novelas es también perceptible la fuerte implicación que los cambios de espacio o de lugar supone para la arquitectura textual —es decir, la estructura interna y externa- de la obra; es un fenómeno rastreable ya en El Lazarillo, El Quijote y muy acentuado en novelas de Balzac (Illusions perdues), Dickens (David Copperfield, Great Expectations), de Galdós (La desheredada), etc. En muchos casos con dichos saltos de lugar se operan mutaciones vitales radicales en los personajes, profundas alteraciones psicológicas de la personalidad, dignas de estudio.

Podemos distinguir dos tipos de personajes si utilizamos como criterio la adaptación a los lugares o espacio en que se mueven: los que manifiestan una cabal y cumplida adecuación, caso común en los protagonistas de corte burgués y realista (David Copperfield, Rastignac en Illusions perdues y Splendeurs et Misères des Courtisanes, Miquis en La desheredada, Feijóo en Fortunata y Jacinta...), y por otra parte, los que manifiestan una extrema y radical inadaptación a espacios e itinerarios (Lucien en Illusions perdues, Pip

\footnotetext{
${ }^{9}$ La novela refleja esa fuerte tensión dialéctica entre clases sociales y sus espacios naturales. Las clases no son ahora impermeables, el cambio y el ascenso/descenso empiezan a sentirse como aspiración posible y realizable. Se rompe el inmovilismo anterior y se produce ascenso y progresión de la burguesía - más tarde el fenómeno alcanza a obreros y proletarios-y, en menor medida, regresión y descenso de la nobleza. Tales vaivenes de progresión/regresión no son uniformes ni alcanzan a todos los niveles e individuos por igual; cada cual protagoniza su lucha por la vida — struggle for life - particular, al igual que la clase a la que pertenece y los espacios urbanos que le son asignados. Estos cambios se pueden interpretar en términos de dialéctica entre «tesis» y «antítesis» en pugna, que dan como resultado una «síntesis» de más o menos larga duración.
} 
en Great Expectations, Malte Laurids Brigge, etc.). Estos últimos suelen dar cabida en su mente a los espacios irreales de la fantasía, la imaginación, las ensoñaciones..., lo que preludia fracasos estrepitosos (Lucien en Illusions perdues, Isidora en La desheredada, Emma en Madame Bovary, Maggie en The Mill on the Floss, Ana Karenina, etc.).

Otra faceta a estudiar sería la que explica la estrecha vinculación existente entre espacio e itinerarios y las técnicas narratológicas descriptivo-narrativas. En muchas ocasiones los paseos por la ciudad sirven de pretexto para que el escritor exhiba sus dotes mostrativas, coloristas, costumbristas. Es el momento propicio para plasmar y trasladar al lector ese hormigueante y rebosante espacio tetradimensional, convertido en crisol polidimensional - fusión de distintos espacios y tiempos en un instante (G. Poulet)-, en la mente hipersensible del creador, admirador de la urbe, que da entonces rienda suelta a su pasión fántica.

Interesa también analizar si los espacios conectados por los itinerarios de los distintos personajes son distantes, tangentes, secantes o más bien concéntricos, lo que nos ofrecerá ciertas pistas en cuanto a las relaciones mutuas. Del mismo modo la unidireccionalidad de itinerarios efectuados por un personaje para introducirse en espacios nuevos y ajenos denota falta de amistad, de intimidad. Si se produce la bidireccionalidad entre los espacios y los distintos personajes, se suele dar la reciprocidad de intercambio, de visitas, de confianza y amistad que secundan la perfecta adecuación espacio-personajes.

Cierta novelística ofrece los espacios urbanos en alternancia - los cerrados y los abiertos- conectados con múltiples itinerarios fánticos, presentados con narración y descripción focalizadas y en movimiento (Balzac, Zola, Galdós, etc.); en otros novelistas hay un claro predominio de los espacios cerrados - lo que no excluye otros espacios abiertos- (Dickens, H. James, etc.); en algunos priman los espacios mentales (Kafka, Dostoievski, etc.); En La desheredada Galdós cuaja el paradigma perfecto de equilibrio y fusión de los espacios, percibido e intuido probablemente en El Quijote.

En la novelística inglesa y alemana existe una mayor propensión hacia los espacios cerrados e interiores; algunos críticos (Rushkin, Hillis Miller, B. Pike), desde interpretaciones psicologistas (H. Miller), explican tal preferencia en la novela inglesa -incluso desde Shakespeare- como símbolo de glorificación y deificación de la mujer, reina del hogar, en un mundo sin creencias y sin Dios. La novelística francesa y española parece dar más cabida a los espacios abiertos de forma general, cuestión que apunta ya a los orígenes de la novela genuina del espacio, que W. Kayser sitúa de forma rotunda en la picaresca y El Quijote.

La semiología de los espacios urbanos pienso que es abierta y no sólo reductible a lo meramente narratológico y literario. En el universo literario caben visiones diversas, encontradas y confluyentes. El espacio urbano novelesco al tiempo que uno es diverso y por ello se revela una fuente inagotable de interpretaciones, que considero complementarias y no excluyentes -enriquecimiento dialógico interdisciplinar que proponen, desde distintos ámbitos, H. Gombrich, R. Nisbet, L. Mumford, C. Guillén, etc.-

Un análisis histórico, marxista, sociológico, no invalida otro psicoanalítico, filosófico o psicologista. Según las épocas y las vogas, las obras son estudiadas bajo ópticas distintas: las de Dickens con angular historicista, psicoanalítico, psicologista (H. Miller, Chesterton), religioso (A. Walsh), etc., las de V. Hugo o Dostoievski desde ciertas visiones religiosas, psicoanalíticas, políticas, etc. La ciudad es marco propicio de con- 
frontación histórica y dialéctica de personajes y espacios que representan el id, el ego y el superego; también es el espacio de los ricos y los pobres, de las virtudes y los vicios, el espacio disfórico de Caín y del hombre en una larga tradición literaria, opuesto a la ciudad de Dios de San Agustín.

La ciudad es un espacio ambivalente por antonomasia en el que conviven todos los contrarios; muchas novelas contemporáneas la presentan como espacio social enfermo y de desintegración, con graves síntomas de deterioro - un frío espacio de la Gesellschaft frente a otro más integrador y humano de la Gemeinschaft anterior al XVIII (I. Watt, B. Pike). Las visiones literarias de Poe, Baudelaire, Balzac, Zola, Brecht, Lorca, etc. también dan pie a las interpretaciones laberínticas, de espacios de opresión, de itinerarios inextricables, ciegos y circulares (R. Gullón), que son bastante coincidentes con el deambular de Rastignac por París, de Raskolnikov por San Petersburgo, de Bloom por Dublín en el Ulysses, de Joseph K. por las calles bajo el castillo en Das Schloss de Kafka, el de Malte Laurids Brigge por París de Rilke, el de Emma Zunz — de apellido simbólicode Borges por Buenos Aires, $y$ tantos otros.

Estoy convencido de que ahondar en el estudio morfosintáctico y semántico del espacio de la ciudad nos abrirá nuevas ventanas a su semiología, otras vías de acceso a este complejo universo de signos, que es posible abordar desde diferentes perspectivas conciliadoras y sumativas, que propone Ortega para comprender el espacio, conexiones y puentes de unión que percibe y defiende Alicia Yllera entre la estilística, la poética y la semiótica para el estudio del fenómeno literario. Muchas son las vías, y no excluyentes, que nos llevan a la nueva Roma, es decir, a buscar la comprensión de este enigmático, prometedor, seductor, laberíntico y caleidoscópico espacio vital del hombre moderno.

\section{REFERENCIAS BIBLIOGRÁFICAS}

AMORós, Andrés (2001): Introducción a la literatura. Madrid: Castalia.

BAKHTINE, Mikhail (1978): Esthétique et théorie du roman. Paris: Gallimard.

Bobes NAvES, Carmen (1993): Teoría general de la novela. Madrid: Gredos.

Bobes Naves, Carmen (1993): La novela. Madrid: Síntesis.

ESTÉBANEZ, José, et alii (1988): Geografía humana. Madrid: Cátedra.

GARRIDO, Antonio (1996): El texto narrativo. Madrid: Síntesis.

Gullón, Ricardo (1980): Espacio y novela. Barcelona: Bosch.

Hillebrand, Bruno (1971): Mensch und Raum im Roman. München: Winkler Verlag.

KANT (1989): Crítica de la razón pura. Madrid: Alfaguara CI.

LuKÁCs, Georg (1979): Balzac et le réalisme français. Paris: Maspero.

MITTERAND, Henri (1986): Le discours du roman. Paris: PUF.

PIKE, Burton (1981): The image of the city in modern Literature. New Jersey: Princeton U.P.

POULET, Georges (1996): Études sur le temps humain. Paris: Plon.

WALSH, Alexander (1971): The City of Dickens. Oxford: Clarendon Press.

YlLeRA, Alicia (1986): Estilística, poética y semiótica literaria. Madrid: Alianza Ed.

ZuBiaURRE, M.` Teresa (2000): el espacio en la novela realista. México: F.C.E. 